\title{
A steep backward masking curve
}

\author{
F. J. LILLIE ${ }^{2}$ AND J. A. GRIBBEN \\ UNIVERSITY OF AUCKLAND, NEW ZEALAND
}

Subjects identified briefly presented pairs of letters which were followed by a bright flash of light after a varying delay. Letter accuracy sharply increased as the flash delay exceeded 30 msec and by 70 msec delay had little further masking effect. Two stimulus durations showed different total accuracy scores, but the masking curves for the two durations were similar.

Perception of a visual stimulus can be impaired or destroyed by a flash of light following the stimulus within a period usually found to be about $100 \mathrm{msec}$ (Raab, 1963). If the stimulus is a near-threshold duration exposure of letters and the adaptation field is dark, the masking effect of the following flash is maximal at 0 msec delay, the effect sharpiy decreasing immediately as the delay is increased and minimal at delays longer than $100 \mathrm{msec}$. Illuminating the adaptation field (Eriksen \& Hoffman, 1963) or decreasing the intensity of the masking flash (Thompson, 1966) yields flatter masking curves, both results consistent with a theory of summation of stimulus and mask luminances, creating contrast reduction of stimulus figure and ground (Eriksen, 1966). An illuminated adaptation field would itself mask the stimulus, lessening any further masking effects of a following flash, and decreasing the masking flash luminance would create less contrast reduction of stimulus figure and ground. In Thompson's study (1966), recognition of the single letter stimulus (A, $T$, or $U$, black on $.200 \mathrm{ft}-\mathrm{L}$ ground) is at a chance level when a .200 $\mathrm{ft}-\mathrm{L}$ flash follows immediately, and improves when either the delay of the $.200 \mathrm{ft}-\mathrm{L}$ flash is increased, or when a less intense flash follows immediately.

The present study explores the backward masking effect when more than one of three letters is given, when the adaptation fleld is dark, and when a following flash more intense than the stimulus is used. As well, stimulus information is varied by exposing the stimulus for different durations. A more briefly presented stimulus should perhaps be easier to mask, the flash reducing figure-ground contrast more than for a stimulus presented longer. Presumably, with intensity-time reciprocity at short durations, a luminance summation hypothesis, by analogy, is applicable here.

Apparatus and Stimuli

Each stimulus display contained two letters, black on off-white cardboard, reflecting $1.7 \mathrm{~mL}$ luminance and seen $1.22 \mathrm{~m}$ distant in a three-field tachistoscope at a duration determined separately for each S. The masking field showed a plain sheet of the same cardboard, reflecting $9.5 \mathrm{~mL}$ and always exposed for $100 \mathrm{msec}$. Both stimulus and masking fields subtended at the eyepiece $6.5^{\circ}$ vertically and $4.3^{\circ}$ horizontally, and were illuminated by whitecoated cold cathode lamps. The adaptation field was dark, with a centrally located dull blue fixation spot 5 ' visual arc in diameter which switched off whenever either the stimulus or masking field was illuminated. The stimulus-delay-mask sequence was initiated by the $S$ himself by pressing a remote microswitch.

Letters were transferable capitals from Letraset 287, $5 \mathrm{~mm}$ high and a mean $3.5 \mathrm{~mm}$ wide. At the viewing distance of $1.22 \mathrm{~m}$, each letter subtended $14^{\prime} \times 10^{\prime}$, the center of each letter $24^{\prime}$ from the center of the fixation spot, the whole display subtending approximately $1^{\circ}$ horizontally. Each display's two letters were different, randomly chosen from the whole alphabet with words and common abbreviations omitted.

Procedure

Four male advanced psychology students, familiar with other tachistoscopic perceptual tasks, served as Ss. Median visual duration thresholds were found for each $\mathrm{S}$, calculated from the last 10 of 20 test stimuli, and were used to determine stimulus exposure values in the practice session $(300,200$, and 100 msec flash delays) and the main experimental session. These exposure values were the S's median threshold and $8 / 10$ of this threshold. After additional practice trials, the main experimental session consisted of 12 sets of 10 stimulus displays shown at threshold or 0.8 threshold exposure, and at one of six masking flash delays: $10,30,50,70,90$, or 110 msec. The Ss were administered all 12 conditions in independently randomized orders of presentation and stimulus sets, with a short rest between each condition. They were told to press the microswitch "when ready" to trigger the stimulus, and were instructed to respond (verbally) to each stimulus. Resulis and Discussion

Results are presented in Fig. 1. Each stimulus set was scored out of 20 for each S. The $9.5 \mathrm{~mL}$ following flash completely masks the stimulus up to a delay of $30 \mathrm{msec}$ and has largely lost its masking effect by $70 \mathrm{msec}$. The effect of delay is significant ( $F=54.00, d f=5 / 15, p<.001$ and $p<.001$ also when data from the 10 and $30 \mathrm{msec}$ delays are dropped from the analysis in the interests of homogeneity). The steepness of the masking curve is pronounced, data from only one delay showing accuracy intermediate between minimal accuracy at short delays 


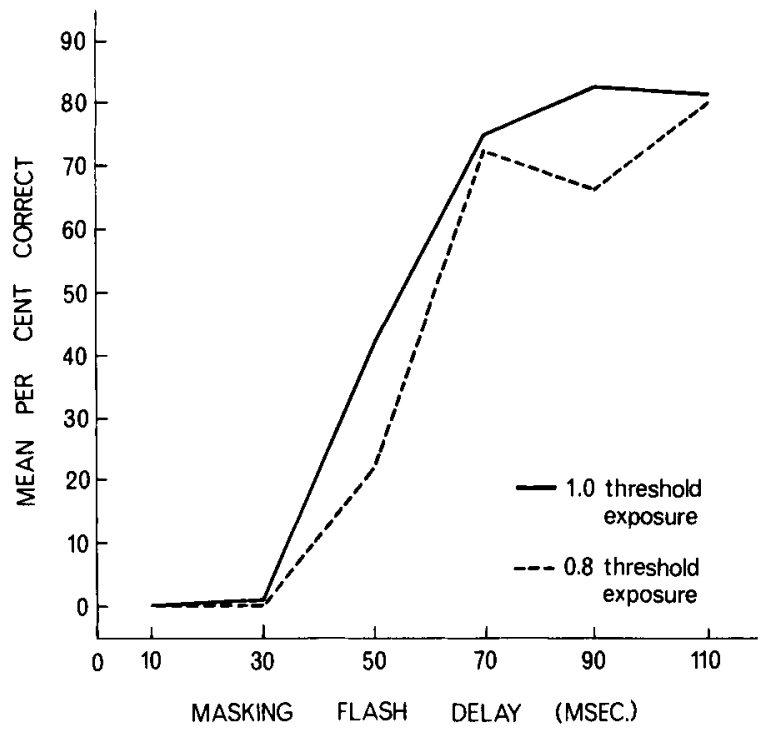

Fig. 1. Mean per cent correct letter identification as a function of masking flash delay. Masking curves shown separately for each stimulus exposure.

and nearly asymptotic accuracy at approximately 70 msec delay. Other data confirm the strong masking effect of light flashes more intense than the stimulus luminance. In a directly comparable experiment, 1 accuracy at $10 \mathrm{msec}$ delay was $0.3 \%$ with a $31.6 \mathrm{~mL}$ flash, $8.1 \%$ with $3.2 \mathrm{~mL}$, and $41.3 \%$ with a $0.3 \mathrm{~mL}$ flash (these results, with two different letters as stimuli, parallel Thompson's result (1966) with one of three letters as stimuli). The steepness of the high luminance masking curve is similar to that sometimes obtained with illuminated adaptation fields and masking fields containing visual noise, so that stimulus contours are randomly occluded (e.g.s Kinsbourne \& Warrington, 1962).

Stimulus exposure duration at threshold values allowed greater accuracy than at 0.8 threshold values $(F=26.57, \quad d f=1 / 3, p<.05$ and $F=34.90, d f=1 / 3, p$ $<.01$ when 10 and $30 \mathrm{msec}$ delay data are omitted).
This reduced accuracy for reduced stimulus presentation time is seen (Fig. 1) at each masking flash delay (except at $10 \mathrm{msec}$ delay, when both are zero); the variability of this reduction across delays is not great enough to show interaction $(F=1.00$, df $=5 / 15$ ). Without any following flash, reduced accuracy would be observed with reduced stimulus exposure; the 0.8 threshold curve may reflect nothing but this lower level of identification at each masking delay. It would perhaps be hazardous to suggest anything more definite about these masked subliminal stimuli in terms of time-intensity relations, although it seems clear from Fig. 1 that reducing stimulus exposure does not lead to an extended masking curve -asymptotic accuracy occurs at the same delay for both stimulus durations.

Individual differences in masking curves (Kolers, 1962; Eriksen \& Steffy, 1964) may be inferred in the present data from the masking (delay by subjects) error variance being ten times as large as the exposure error variance. Two of the four Ss showed mild reversals in increasing accuracy as delay increased, but these reversals do not alter the general monotonic masking function displaced by the bright masking flash.

\section{References}

ERIKSEN, C. W. Temporal luminance summation effects in backward and forward masking. Percept, \& Psychophys., 1966, 1, 87-92.

ERIKSEN, C. W., \& HOFFMAN, M. Form recognition at brief durations as a function of adapting field and interval between stimulations. $J$. exp. Psychol., 1963, 66, 485-499.

ERIKSEN, C. W., \& STEFFY, R. A. Short term memory and retroactive interference in visual perception. J. exp. Psychol., 1966, 68, 425-434

KINSBOURNE, M., \& WARRINGTON, E. K. The effect of an aftercoming random pattern on the perception of brief visual stimuli. Quart. J. exp. Psychol., 1962, 14, 223-234.

KOLERS, P. A. Intensity and contour effects in visual masking. Vis. Res., 1962, 2, 277-294.

RAAB, D. H. Backward Masking. Psychol. Bull., 1963, 60, 118-129. Notes

1. This paper is based on part of an M. A. thesis by the senior author at the University of Auckland.

2. Now at Psychology Dept., Institute of Psychiatry, London. 